\section{Powers of the G.M.C.}

SIR,-In his letter on the powers of the G.M.C. Professor D. A. K. Black (3 May, p. 310) seems to overlook certain points. If his contention were correct there would, I suggest, be no need for the Medical Act, 1956 , to require the setting-up of a Medical Disciplinary Committee, which is independent of the Council in its decisions. This provision for a separation of functions would appear to meet Professor Black's objection and to put the G.M.C. in a similar position to the Pharmaceutical Society, whose structure and powers in relation to discipline are not significantly different.

Any difficulty in the G.M.C. taking action seems to lie in the rules of the Disciplinary Committee, which provide for complaints coming from outside and not originating in the G.M.C. ${ }^{2}$ The corresponding regulations of the society's disciplinary committeethat is, the Statutory Committee-have no such limitation. ${ }^{3}$ Although a complaint may be made by anyone, virtually all complaints to the Statutory Committee are made by the council of the society, who regard it as their responsibility not only to give guidance to pharmacists on matters of professional conduct but also to take the initiative in formulating and submitting complaints to the committee from information within their knowledge, however obtained.

Since the Disciplinary Committee makes its own rules subject to Privy Council approval-as does the society's Statutory Committee-the remedy, if any is needed, would appear to lies in the G.M.C.'s own hands.-I am, etc.,

\section{F. W. ADAMS,} Sometime Secretary and Registrar, the London N.W.3.

REFERENCES

1 Pharmacy Act 1954 Ch. 61. S.7, S.8, S.10, First Schedule. Medical Act 1956 Ch.

S.1. 1958 No. 1805 , Ch.76.

\section{Treatment of Angina Pectoris}

SIR,-Your leading article on the treatment of angina pectoris (19 April, p. 134) hardly clarifies the present situation. In essence it recommends that anginal patients should eat less, smoke less, do more, and occasionally take trinitrin. This advice suggests that there has been little advance in therapy in the last 30 years. A practitioner using "one of the three new drugs" (they are seemingly indistinguishable in efficacy) does so at his own risk and with the knowlodge that while they may help some patients they may harm others-an observation applicable to all drugs of proved value.

Not only does the article fail to give adequate guidance, but it is in fact misleading. For example, why does your leading article, when insisting that propranolol works by an action other than beta blockade, ignore the recent letter in the B.M.F. (1 February, p. 318) which discusses this problem. Could it be that authors of leading articles do not read their own journals? Certainly the points raised by Dr. A. M. Barrett merit discussion even if they are not accepted. In particular, he makes the point that expropranolol, which has only quinidine-like activity, is ineffective in angina, whereas I.C.I. 50,172, a compound with only beta-blocking activity and no quinidine-like activity, is effective This raises serious doubts as to the validity of the opinion so freely given in your leading article.

The mode of action of oxprenolol (Trasicor) is not discussed. Oxprenolol, like propranolol, has quinidine-like properties. ${ }^{2}$ By omitting this important piece of pharmalogical information it is implied that oxprenolol differs from propranolol. Dr. Barrett's letter mentions 17 double blind studies with propranolol involving 370 patients. Yet the only guidance to the literature given by your leader to the busy practitioner is a reference to one study published in 1964 .

The discussion of the long-term management of angina quotes Oliver's list of predisposing factors yet omits hyperlipidaemiathe one factor given most weight by Oliver." Practitioners are well aware of the importance of hyperlipidaemia in the pathogenesis of atherosclerosis. Why does your leader omit it ? It may be that some form of positive therapy might have to be suggested rather than vague generalizations such as "reduction of mental stress and the preservation of hope." The anginal patient requires treatment rather than pious aspiration accompanied by a list of do's and don'ts.

Finally, your leader writer fails to distinguish between approved names and trade mark names. Trasicor is a trade mark name. The approved name is oxprenolol. Since the approved names of Inderal and Cordilox were used it would have been more consistent and just to the firms concerned if the approved name of Trasicor had been used.-I am, etc.,

\section{Pastures Hospital} Mickleover,
Derby.

\section{J. C. M. WILKINSON.}

\section{REFERENCES}

Brunner, H., Hedwa, P. R., and Meier, M. 1968, Arzneimittel-Forschung, 18, 164 Oliver, M. F., and Stuart-Harris, C. H., British

** The approved name oxprenolol was assigned by the Pharmacopoeia Commission last November to 1-(o-allyloxyphenoxy)-3isopropylaminopropan-2-ol, of which a coded product called CIBA-39089 was stated to be the hydrochloride. CIBA-39089 (the name appearing in the booklet Approved Names dated January 1969) is the same as Trasicor. The drug is not yet generally available in Britain (3 May, p. 325).-ED., B.M.F

\section{Drug Names}

SIR,-It is high time you adopted a consistent policy regarding the use of trade names of approved drugs in the B.M.F. Most general practitioners are accustomed to using many trade names in their drug prescribing; indeed, new drugs are often only available in trade preparations.

In the B.M.F. (3 May, p. 287) an drticle of great interest to general practitioners describes a double blind trial of the relative merits of isoprenaline, orciprenaline, and salbutamol. We are told that the latter is the best in acute asthma, but nowhere are we given the trade name. Why this false modesty?
If I prescribe " inhalations of salbutamol" my local chemist is bound to ring up and ask me what it is and who manufactures it. It isn't listed in the B.N.F. or in Martindale or even in M.I.M.S. I can only find out by scanning the small print in the trade ads.

May I suggest that in future you print a full list of all the proprietary products at the end of any article describing a new drug ? -I am, etc.,

Olney, Bucks. Nigel Swallow.

\section{Improved Control of Long-Term Anticoagulant Therapy}

SIR,-Following the publication of the working party on anticoagulant therapy in coronary thrombosis of the Medical Research Council (8 February, p. 335) and subsequent correspondence, it is worth recording further results from a comparison of the partial thromboplastin test (P.T.T.) and the prothrombin ratio, reported last year. ${ }^{1}$

Since the beginning of 196763 bleeding episodes have been found in 52 patients during long-term oral anticoagulant treatment. Twenty-four patients had suffered from myocardial infarction, 24 patients had suffered from venous thrombotic lesions, and four patients with mitral valve disease had suffered from embolic attacks. Bleeding varied from subcutaneous bruising, haematuria, or gastrointestinal haemorrhage to small subconjunctival haemorrhages. They followed discontinuation of barbiturates, treatment with broad-spectrum antibiotics, ingestion of the wrong strength of tablets by the patient, treatment with certain tranquillizers, or were unexplained. When the P.T.T. exceeded 70 seconds haemorrhages occurred in some patients, regardless of the prothrombin ratio result. Subconjunctival haemorrhages did not appear to be simply related either to excessively raised prothrombin ratios or to prolonged P.T.T. results, but may have been related to excessive coughing.

In the earlier paper ${ }^{1}$ it was shown that raised prothrombin ratios with normal P.T.T results were found in the early stages of anticoagulant therapy. It is suggested that this could lead to a false sense of security, since a patient with a normal P.T.T. result $(35-45$ seconds) is probably not protected from a further thrombotic attack, whatever the prothrombin result (which reflects depression of factor VII in particular). Even the use of the thrombotest may be misleading, since this latter test is sensitive to depression of factor $\mathrm{X}$, whereas the P.T.T. detects changes in factor IX.

It is therefore again suggested that the P.T.T. is very useful in the early stages of treatment (as it can be used to control heparin dosage), and also in the latter stages of treatment, when excessive reduction of plasma factor IX may result in bleedingthat is, a secondary complicated "Christmas disease" with reduced plasma factors II, VII, and $\mathrm{X}$ also. Utilizing non-specific surface activators (kaolin, celite, bentonite, etc.) and either platelet substrate or its substitute in optimal amounts with the patient's plasma, this is a cheap, reproducible, and easily standardized test (unlike many thromboplastin preparations used for the prothrombin test). It has been found to be very useful, 
giving a better therapeutic range of control than the prothrombin test or related tests. -I am, etc.,

Frenchay Hospital,
Bristol.
2 E. D. EASTHAM.
Eastham, R. D., British Medical fournal, 1968,
2, 337.

\section{Supratentorial Intracranial Abscess}

SIR,-Professor W. Bryan Jennett's letter (3 May, p. 310) contains a most serious inaccuracy. He writes of our " recommendation to delay treatment for 48 hours while awaiting scanning in any patient suspected of a brain abscess." In fact in the review (5 April, p. 7) we accepted (but did not recommend), such a delay only when the patient remains alert, and that during that period treatment with high dosage penicillin should be instituted. It is important that such an alarming and indeed surprising error in his letter should not be allowed to pass unnoticed.

Mr. D. W. C. Northfield (19 April, p. 184) also raises a few points with which I should like to deal as briefly as possible.

Apropos the use of ventriculography and undesirable reactions, he writes that ". . . it has certainly been my impression that they are frequent. ..." Our review has simply replaced impression by fact; deterioration in $8 \%$ is indeed serious, but this figure was viewed in the light of the overall mortality of $40 \%$, so much of which was due to failed localization. The use of the site of E.N.T. focus in placing a burr hole is certainly old teaching, but unfortunately this teaching has been forgotten in that in our series this method was used 35 times in the 100 cases from 1951 to 1957 but only 23 times in the 100 cases from 1962 to 1967 . Brain scanning does demonstrate accurately the site of abscess and not simply oedema, and we have a patient treated in 1969 whose arteriogram and brain scan confirmed this point.

In discussing the accuracy of arteriography as apparently demonstrated in Krayenbühl's series it is surprising that $\mathrm{Mr}$. Northfield has extrapolated the low mortality to indicate the accuracy of arteriography, and that he has not realized that records of low mortality are valueless unless factors such as time of referral and level of consciousness on admission are considered. Weber, ${ }^{2}$ in his review of 51 arteriograms in patients with cerebra abscess, found 13 in whom the abscess was clearly demonstrated by vessels in the capsule, or blush, but the length of history in these patients varied from 10 days to eight months, and he does not indicate how many of these 51 arteriograms provided the neurosurgeon with accurate localization for successful treatment of the abscess. Perhaps the neurosurgical fraternity is by now converted to the use of massive doses of antibiotics; I simply recorded the fact that, even during 1967, the fraternity in the particular centres studied was not on average obeying that conversion.

The method of craniotomy and decompression introduced by Clovis Vincent ${ }^{3}$ may well have been an advance in that era, but in the paper to which Mr. Northfield refers the conclusions are based upon the records of only five patients, in none of whom was the history shorter than one month, and the levels of consciousness of the patients by the time they reached the neurosurgeon were such that they were able to speak. In only one patient (Case 3) was a well-formed capsule not present at the time of either aspiration or excision. Such relatively chronic cases, although requiring nicety of judgement in their management, no longer provide the major mortality. We attempted to define a method of management for the acute case with rapidly deteriorating level of consciousness based upon a factual survey, for, as Vincent wrote in 1937, " $F u s q u$ 'ici ces formes n'ont donné lieu qu'à des échecs chirurgicaux. Elles n'en donneront plus le jour où nous saurons parer intelligemment à l'infection et à l'odeme cérébral massif et extensif. Nous reviendrons un jour sur ce sujet."-I am, etc.,

\section{Wessex Neurological Centre, Southampton General Hospital,
Southampton, Hants. \\ REPBRENCBS \\ ${ }^{1}$ Krayenbühl, H. A., Clinical Neurosurgery, 1967, $14,45$. \\ Vincent, G., Neuro-Chirurgie, 1960, 6, 317.4. fournal de Chirurgie, 1937, 49, 1. \\ John Garfield.}

\section{Abortion Act in Practice}

SIR,-Dr. R. W. Penny (26 April, p. 248) raises a very important issue in pointing out the many breaches of ethical standards occasioned by the Abortion Act. These are likely to become more frequent as abortion centres proliferate throughout the country.

The chapter on medical ethics in the B.M.A. Handbook lays down quite clearly the obligations of a doctor who is consulted by another doctor's patient. It recommends that "a practitioner ought not to accept as his patient, save with the consent of the colleague concerned; ... Any patient who at the time of the application is under active treatment by a colleague, unless he is personally satisfied that the colleague concerned has been notified by the patient or his representatives that his services are no longer required."

It follows that any practitioner, whose treatment of pregnancy is interfered with by a colleague without his knowledge or against his advice, has a perfect right to make a complaint to the Central Ethical Committee of the B.M.A. Furthermore, if every aggneved practitioner took this course of action, not only would it strengthen the hands of the Ethical Committee in the carrying out of its duties, but it might have a beneficial effect on his blood pressure and coronary circulation.-We are, etc.

Birmingham 30.

D. C. Sturdy.

R. J. D. BROWNE.

\section{Synacthen Depot in General Practice}

SIR,-In reply to Drs. J. E. Murphy and J. F. Donald (12 April, p. 119) I would again reiterate that the conditions, or rather the variety of symptoms, that they treated are not indications for corticotrophin therapy -namely, fibrositis (18 cases), lumbago/back

strain (11 cases), also sciatica, muscle strain/ injury, etc. The use of corticotrophin as an esoteric aspirin will only add a new set of complications to those we already fear from long-term therapy. Short courses, as they propose, for the relief of the above symptoms will undoubtedly suppress these symptoms, and in fact in some cases lead to delay in diagnosis of potentially serious diseases such as giant-cell arteritis and other collagen diseases that may present with these complaints.

Their original letter (1 February, p. 317) contrasts strangely with the advice of the February issue of Prescribers' Fournal' (Dr. Barbara Ansell) with regard to the treatment of rheumatoid disease: "Corticosteroids and corticotrophin are powerful anti-inflammatory drugs but should not normally be prescribed unless the patient shows signs of the systemic complications of rheumatoid disease or suffers severe joint pain and functional disability in spite of adequate treatment by general and local rest, appropriate splintage, physiotherapy, and conscientious administration for at least six to 12 months of one or more analgesic drugs." Space alone caused me to omit any reference to the proposed doubleblind trial. I suggest that they take the above advice of Dr. Ansell as a text for their protocol and then such a double-blind study might not only be statistically significant but also medically worthwhile, which would be more important.

Their reference to pain at site of injection being due to our technique of administration is a little surprising, since in their original letter '( 1 February) they quote only four references, ${ }^{2-s}$ and all of these mention pain at injection sites.

I apologize for some display of exasperation in this letter, but I deprecate the fact that after two decades of bitter lessons with regard to steroid and corticotrophin therapy some new folly should now appear.-I am, etc.,

Belfast.

J. A. Weaver.

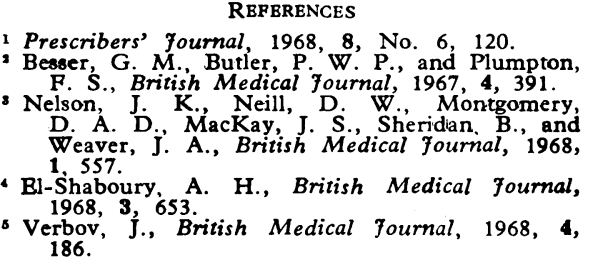

186.

응

